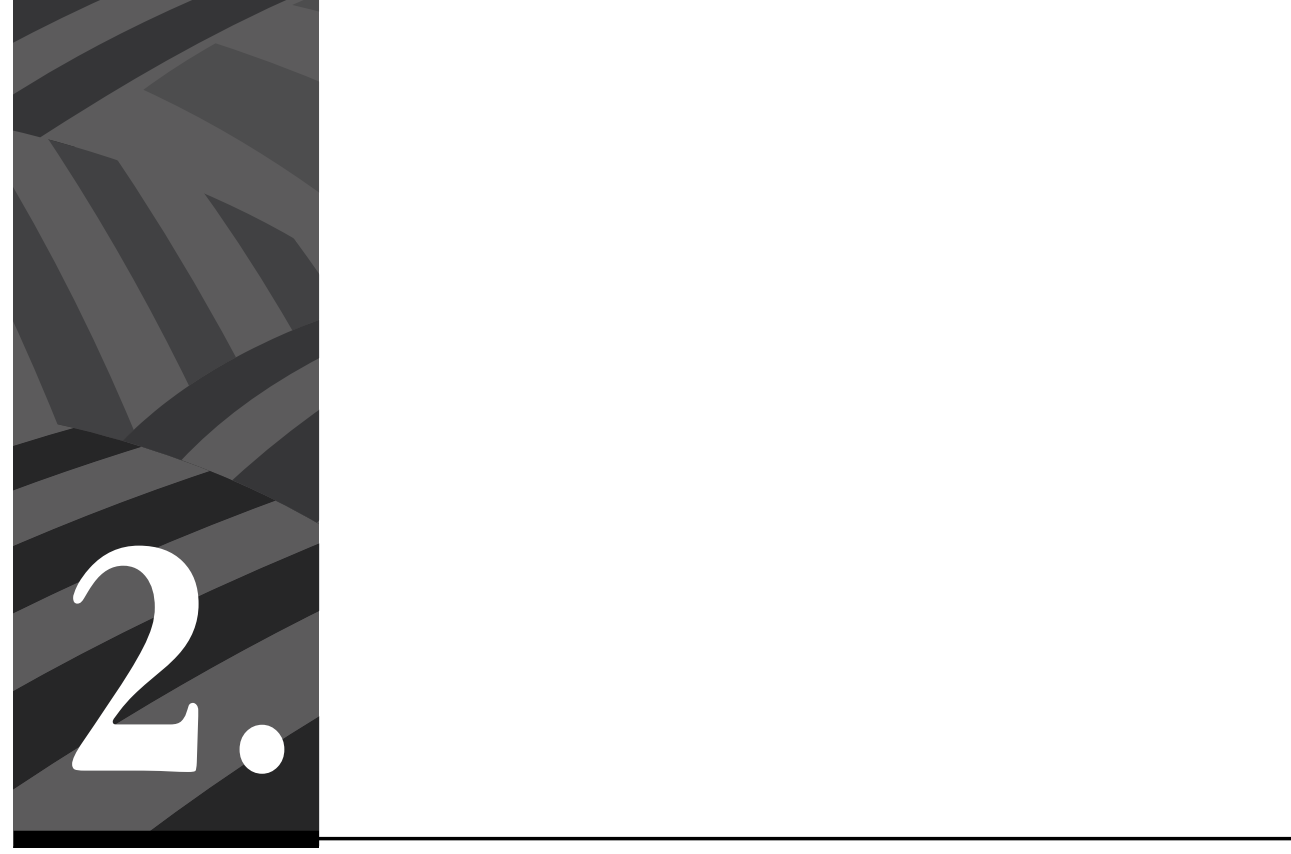

La paz de Colombia en un incierto entorno internacional 


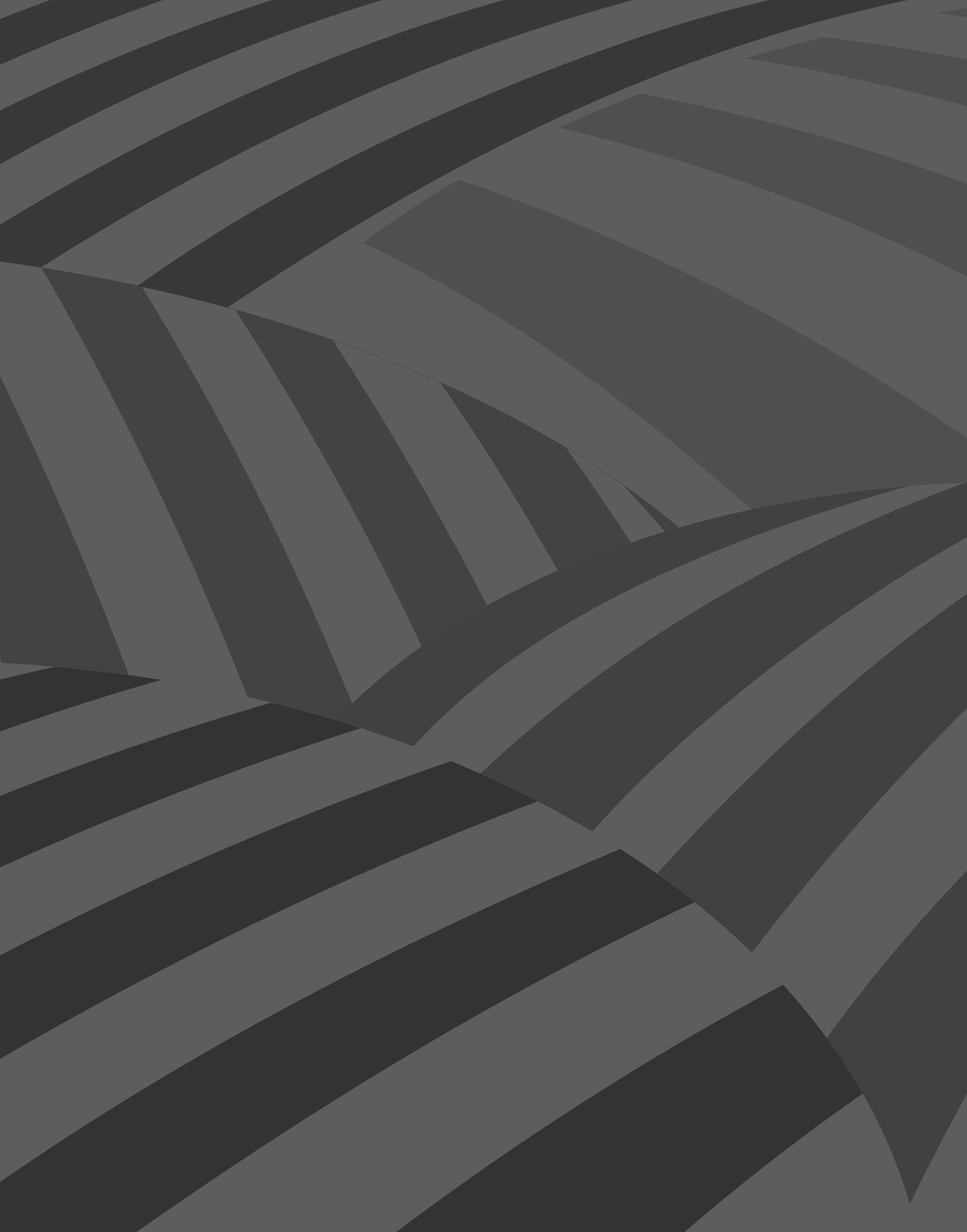




\section{La paz de Colombia \\ en un incierto entorno internacional}

Por Consuelo Ahumada*

DOI: https://doi.org/10.54118/controver.vi217.1236

Resumen: En el presente artículo se buscó establecer la interrelación existente entre el cambiante contexto internacional, regional y nacional, y la implementación del Acuerdo Final de Paz entre el Gobierno nacional y las antiguas FARC-EP, en los cuatro años y medio transcurridos desde su firma en noviembre de 2016. Se parte del planteamiento de que la coincidencia temporal entre los gobiernos de Obama en EE. UU. y Santos en Colombia fue fundamental para la concreción y avance de los puntos acordados. A su turno, la concurrencia de los gobiernos de Trump y Duque fue también determinante en la crisis y estancamiento, cuando no franco retroceso, en la implementación del Acuerdo.

Palabras clave: contexto internacional y regional, orden global, acuerdo final, derechos humanos

\section{Colombia's Peace in an Uncertain International Environment}

Abstract: This article establishes a relationship between a changing international, regional and national context and the implementation of the Final Agreement between the government and FARC, in the four years passed since it was signed. It argues that the temporal concurrence of the governments of Obama and Santos was fundamental for the concretion and advance of the agreement. For its part, the coincidence between the governments of Trump and Duque was instrumental for the crisis, stagnation and even backsliding in its implementation.

Keywords: International and regional context, global order, final agreement, human rights.

Cómo citar este artículo: Ahumada, Consuelo (2021). La paz de Colombia en un incierto entorno internacional. Revista Controversia, 217, 53-86.

* Profesora Facultad de Ciencias Sociales y Humanas, Universidad Externado de Colombia. Ph.D en Ciencia Política con énfasis en estudios latinoamericanos, New York University (1995). Miembro de número de la Academia Colombiana de Ciencias Económicas ACCE e integrante de su Mesa Directiva. Vicepresidenta de la Asociación Colombiana de Economía Crítica, ACECRI. Correo electrónico: cahumadabg@gmail.com 
Fecha de recepción: 14 de febrero de 2021

Fecha de aprobación: 15 de abril de 2021

\section{Introducción}

El comienzo de las negociaciones llevadas a cabo en La Habana entre las antiguas FARC-EP y el gobierno de Juan Manuel Santos en el año 2012, la firma definitiva del Acuerdo Final para la terminación del conflicto y la construcción de una paz estable y duradera (en adelante Acuerdo de Paz o Acuerdo) cuatro años después (noviembre de 2016), y el inicio de su implementación ocurrieron en medio de unas condiciones internacionales, regionales y nacionales cambiantes. Entre el primero y el último de estos sucesos se acentuaron algunas tendencias regresivas que han incidido de manera notoria en el desarrollo del proceso.

El impacto del prolongado conflicto armado en el país ha sido enorme en cuanto a vidas sacrificadas, desapariciones, atropellos, desplazamiento forzado y todo tipo de violencias. Sus efectos económicos, sociales, políticos y culturales siguen siendo graves, como ha sido documentado por múltiples informes y escritos tanto nacionales como internacionales. ${ }^{1}$ Por ello, la negociación y la firma del Acuerdo de Paz suscitaron expectativa y entusiasmo en el mundo entero. Pese a las dificultades y a las fuertes contradicciones en torno al proceso, después de su suscripción definitiva se inició su puesta en práctica en condiciones relativamente propicias y se contó con el respaldo de organismos internacionales y de muchos países.

Pero este ambiente nacional favorable se modificó de manera decisiva a partir del triunfo de Iván Duque y del Partido Centro Democrático en las elecciones presidenciales de 2018. Se impuso así la visión de los enemigos del Acuerdo de Paz desde el Gobierno nacional. Siguiendo

1 El informe Basta ya! Colombia: memorias de guerra y dignidad, elaborado y publicado por el Centro Nacional de Memoria Histórica (2013), es fundamental para la comprensión y análisis de las múltiples dimensiones del conflicto armado colombiano. 
los criterios de su partido, el nuevo presidente se ha empeñado en deslegitimar y entrabar la ejecución integral de los puntos del Acuerdo desde el Ejecutivo, el Congreso, la Fiscalía y, en general, los organismos de control, al frente de los cuales ha nombrado a personas muy cercanas y afines con dicho propósito.

El incumplimiento del Acuerdo de Paz ha sido un factor fundamental en la reactivación e intensificación del conflicto en diversas zonas del territorio nacional. En medio de una creciente concentración del poder, su lema "Paz con legalidad" marcó su distanciamiento respecto a los compromisos derivados del Acuerdo, y en particular frente al desarrollo del esquema de justicia transicional, cuyo mecanismo, la Jurisdicción Especial para la Paz (JEP), es el "componente de justicia del Sistema Integral de Verdad, Justicia, Reparación y no Repetición (SIVJRNR) allí dispuesto. El nuevo gobierno significó también el retorno a los postulados y prácticas de la Política del Seguridad Democrática del gobierno de Álvaro Uribe Vélez (2002-2010). ${ }^{2}$

En concordancia con lo anterior, en este artículo se busca establecer la compleja interrelación existente entre el cambiante contexto internacional, regional y nacional y la implementación del Acuerdo Final, en el curso de los cuatro años y medio transcurridos desde su firma. Se parte del planteamiento de que la coincidencia temporal entre los gobiernos de Barack Obama en la Casa Blanca (2009-2017) y Juan Manuel Santos en la Casa de Nariño (2010-2018) fue fundamental para la concreción y avance de los puntos acordados, al igual que el papel mediador desempeñado por los gobiernos de Cuba y Venezuela. En contraposición, la concurrencia de las administraciones de Donald Trump (2017-2021) e Iván Duque

2 El 17 de diciembre de 2018 el Alto Consejero para el Posconflicto, Emilio Archila, presentó la Política de Estabilización denominada "Paz con Legalidad”. Se anunció como una política centrada en el propósito de construir un país de equidad, desde la legalidad (Presidencia, 2018). En sus intervenciones, el primer mandatario y sus funcionarios insisten en contraponer este concepto con la visión recogida en el Acuerdo Final en torno a los procesos que deberán aplicarse a los excombatientes, en el marco de la justicia transicional. 
(2018-2022) y el endurecimiento de la política de la Casa Blanca frente a los dos países caribeños han sido determinantes en la crisis y estancamiento, cuando no franco retroceso, en la implementación del Acuerdo Final. En este marco, los organismos internacionales, en particular la Organización de las Naciones Unidas (ONU) y la Corte Penal Internacional (CPI) le han brindado un respaldo decisivo al proceso.

Este análisis se desarrolla en tres partes. En la primera se examinan algunos de los principales componentes del entorno internacional y regional, y su incidencia en el Acuerdo de Paz; la segunda se centra en las tensiones existentes entre el Gobierno colombiano y las Naciones Unidas, en lo que respecta al cumplimiento del Acuerdo y en cuanto a las perspectivas de cambio con el nuevo gobierno de EE. UU.; y, por último, se plantean algunas conclusiones.

Cuando han transcurrido casi tres años de la administración Duque, el Acuerdo atraviesa por difíciles momentos. Sus puntos centrales no fueron incluidos en el plan de desarrollo Pacto por Colombia, pacto por la equidad (2018-2022) ni recibieron asignación apropiada de recursos en el presupuesto nacional (CINEP/PPP, 2019). La única preocupación del presidente Duque frente a lo pactado en el Acuerdo pareciera ser la reincorporación de los excombatientes. Sin embargo, muchos de ellos han sido asesinados, al igual que cientos de líderes y lideresas sociales de las más diversas causas, a lo largo y ancho del territorio nacional. ${ }^{3}$

Frente a ello, la respuesta de las autoridades ha estado marcada por indolencia, displicencia y cinismo. En muchos de los crímenes ha habido denuncias de complicidad por parte de agentes del Estado, y la mayoría de estos han sucedido en territorios con fuerte presencia militar. Altos funcionarios insisten en minimizar y banalizar la situación, muchas

3 Según Indepaz (2021), 267 excombatientes y más de 1000 hombres y mujeres defensores de derechos humanos y de causas sociales han sido asesinados entre la firma del Acuerdo y abril 19 de 2021. Según la misma fuente, en el 2020 se registraron 91 masacres con 381 víctimas y en el 2021, con corte al 3 de mayo, se habían producido 35 masacres, con 132 víctimas. 
veces con estigmatizaciones y justificaciones, y en responsabilizar al narcotráfico en general y al mismo Acuerdo de Paz. Entre tanto, ha sido permanente e incisivo el ataque del Gobierno a las entidades del SIVJRNR, ${ }^{4}$ en particular a la JEP, y a su función crucial de conocer y administrar justicia en el caso de los delitos cometidos en el contexto del conflicto armado, con anterioridad al 1 de diciembre de 2016.

En el plano internacional, la política del gobierno colombiano ha estado signada por un alineamiento incondicional con la agenda de la extrema derecha, que tuvo fuerte impulso durante el paso de Donald Trump por la Casa Blanca. Duque no solo acogió con entusiasmo sus políticas para Colombia y sus aventuras militares en la región, sino que reiteró con acciones y palabras su disposición de afianzar todavía más su alianza con Washington, en una región con tanta efervescencia política y social como América Latina.

En efecto, durante los primeros días de su gobierno, el presidente colombiano dejó en claro cuáles serían los ejes de su política exterior y las acciones que adelantaría: i) defensa y fortalecimiento del Sistema Interamericano de Derechos Humanos, así como de la oEA; ii) avance en la Alianza del Pacífico y otros mecanismos regionales de integración; y iii) retiro de la Unión de Naciones Suramericanas (Contexto Diario, 2018).

El 26 de septiembre de 2018, en su primera intervención ante la Asamblea General de la ONU, señaló al narcotráfico como "una amenaza global" y se refirió al "fin de la dictadura, el retorno a la democracia y la plena libertad [como] único camino posible" para Venezuela. "La libre determinación de los pueblos no puede ser manipulada para convertirse en la libre determinación de los opresores”, afirmó, y convocó a la

4 El SIVJRNR está integrado por tres entidades: la JEP; la Comisión para el Esclarecimiento de la Verdad, la Convivencia y la no Repetición; y la Unidad de Búsqueda de Personas Desaparecidas en el contexto y en razón del conflicto armado. Este sistema, incorporado a la Constitución colombiana mediante el Acto Legislativo 01 de 2017, es el tema central del punto 5 del Acuerdo de Paz: Acuerdo sobre las víctimas del conflicto. 
comunidad internacional a defender esta causa. Se materializaba así un giro frente a la postura internacional del gobierno anterior, centrada en la defensa del Acuerdo de Paz, al tiempo que ratificaba su identificación plena con la agenda estadounidense para la región: lucha antinarcóticos, control pleno del Sistema Interamericano y cerco a Venezuela (Gobierno de Colombia, 2018). ${ }^{5}$

Al respecto, Ana María Rodríguez (2020), integrante de la Comisión Colombiana de Juristas, señala tres rasgos muy precisos, característicos de la conflictiva relación del Gobierno colombiano con los organismos internacionales. El primero, la distracción, que se expresa en eventos como la intervención de Duque en la Asamblea de la ONU en 2019, cuando se centró en Venezuela y utilizó fotografías falsas con las cuales pretendió probar su supuesto apoyo al ELN. El segundo es la confrontación, expresada en su respuesta agresiva ante distintos informes internacionales; y, el tercero, la restricción, manifiesta en su intento de limitar las funciones del Sistema Interamericano de Derechos Humanos, en particular en lo que respecta a la defensa de los derechos que lo identifican. En este punto hay que mencionar la nefasta labor del secretario general de la OEA, Luis Almagro, con el apoyo de Alejandro Ordóñez, representante de Colombia ante esa organización, en diversos asuntos, pero en particular en los que atañen a los gobiernos de los países andinos.

Por su parte, Gimena Sánchez-Garzoli, de Washington Office on Latin America, y Lisa Haugaard, de Latin America Working Group (2020), anotan que Trump modificó el enfoque de la administración Obama de apoyar el Acuerdo de Paz y su implementación, y volvió a centrarse en la lucha antinarcóticos, con un nuevo énfasis: "Usar a Colombia para presionar un cambio de régimen en Venezuela” (p. 402). Esta situación

5 Vale aclarar que aquí no se pretende en manera alguna evaluar los errores y aciertos de las políticas desarrolladas por el gobierno de Venezuela tanto en lo nacional como en lo internacional. Solo se examina lo concerniente a la agresión de que ha sido objeto este país por cuenta de los gobiernos de Estados Unidos y de Colombia. 
se convirtió en un factor adicional que atenta contra la paz en Colombia y la región, ambas indisolublemente ligadas.

\section{El cambiante contexto internacional}

\subsection{Orden global: crisis económica y fortalecimiento de la extrema derecha}

Durante el período de negociación y firma del Acuerdo de Paz se afianzaron aún más las políticas neoliberales en el mundo entero, como resultado de la grave crisis financiera y económica que estalló en 2008 en EE. UU. y se propagó después por Europa y el resto del mundo. En ello fueron determinantes las medidas que se adoptaron para enfrentar la crisis por parte de los países poderosos y las instituciones financieras internacionales. Una vez se recuperaron los banqueros, responsables de la debacle, el peso de la superación de la crisis recayó sobre los trabajadores/as y los sectores más vulnerables de la sociedad. Se incrementaron así las políticas de restricción del gasto público, la privatización, el debilitamiento del estado de bienestar, así como de los derechos laborales y sociales conquistados durante décadas. El desastre de la salud pública y la seguridad social, puesto en evidencia por la pandemia, es resultado de esas medidas.

En el plano político, en el mundo se acentúo una tendencia muy regresiva, marcada por el auge y fortalecimiento de la extrema derecha. Se consolidó así la combinación de una mayor exclusión económica y social con el ataque al Estado de derecho y a la legalidad internacional, en una deriva cada vez más autoritaria e incluso de corte fascista. En diversas partes del mundo emergieron o se consolidaron gobiernos, coaliciones y partidos dispuestos a defender ese ideario a como diera lugar.

El lema "Haz América grande otra vez" (Make America Great Again -MAGA), representativo del expresidente Trump y sus seguidores, se concretó en la defensa a ultranza de un nacionalismo regresivo, unilateral, de desconocimiento de la institucionalidad internacional y de los 
acuerdos multilaterales, de la prevalencia de la agresión y del discurso incendiario sobre el diálogo y la negociación. Se identificó plenamente con el supremacismo blanco, tan arraigado en la historia del país del Norte, y con todos sus componentes: fanatismo religioso, racismo y xenofobia, valores patriarcales y homofobia; mayor exclusión económica y social; y profundo desprecio por los sectores más pobres y vulnerables, incluidos los inmigrantes, una expresión clara de "aporofobia”, término acuñado por Adela Cortina. ${ }^{6}$

En el caso colombiano, el afianzamiento de estas tendencias excluyentes y autoritarias, sumadas a los intereses y valores ligados al control territorial y al poder de la hacienda, así como los vínculos con el negocio de la droga y el paramilitarismo, identifican el proyecto del Centro Democrático y, sin duda, constituyen el factor fundamental que explica las dificultades del Acuerdo de Paz.

Regresemos a la economía global. Asediados por la fuerte competencia que prevalece y para contrarrestar los efectos de la crisis, los países más desarrollados intensificaron la búsqueda de mejores condiciones para el comercio, la inversión y el acceso a recursos estratégicos en el mundo entero, en particular en los territorios del Sur. En consonancia con ello, las dos últimas décadas han registrado la expansión del modelo minero y agroexportador. Se trata de la guerra por el control de los recursos, cada vez más codiciados, que reemplazó la confrontación ideológica de la Guerra Fría (Klare, 2001).

El modelo minero-exportador, tan generalizado en nuestra región, tiene un impacto negativo que ha sido bastante documentado tanto en lo que respecta a los reducidos ingresos para los países dueños de los recursos y la precariedad laboral del sector como por su efecto devastador en la crisis climática. Consideración similar puede hacerse de los

6 De acuerdo con Cortina (2000), la aporofobia podría caracterizarse como “el odio, repugnancia u hostilidad ante el pobre, el sin recursos, el desamparado”. 
grandes negocios agroindustriales que proliferan en el mundo entero, en detrimento de las economías campesinas. También en este marco, los llamados "mercados de futuros de bienes primarios" (Commodity Future Markets) y la especulación financiera en torno a ellos adquieren cada vez más relevancia. Es decir, se afianza la conexión estrecha entre el extractivismo, los agronegocios y los intereses financieros.

De otro lado, además de la gravísima crisis sanitaria, la pandemia ocasionó el derrumbe de la economía mundial, cuyas perspectivas parecían oscuras desde tiempo atrás. Los organismos internacionales venían alertando sobre la inminencia de una nueva recesión, similar a la de 2008 (ONU, 2012, 2019). Por supuesto que la magnitud e impacto de la crisis actual ha superado todas las predicciones.

No obstante, en tiempos tan difíciles, se ha producido un incremento notorio de las ganancias de las grandes empresas en el mundo. De acuerdo con Gneiting, Lusiani y Tamir (2020), la crisis desatada es el resultado de un modelo económico que ha llevado a una mayor acumulación de la riqueza:

La pasada década ha sido la más rentable de la historia para las grandes empresas: las 500 mayores del mundo, incluidas en el listado Global Fortune, incrementaron sus beneficios en un $156 \%$ entre 2009 y 2019 , pasando de 820.000 millones de dólares a 2,1 billones durante ese periodo. (p. 3).

Otro informe más reciente de la misma entidad señala que la concentración económica se volvió todavía más grave con la pandemia, que incrementó la desigualdad en todos los países del mundo al mismo tiempo, en "una situación sin precedentes desde que existen registros (...) El virus ha puesto al descubierto y ha exacerbado las desigualdades económicas, de género y raciales, a la vez que se ha alimentado de ellas” (Berkhout et al, 2021, p. 2). 
Las prioridades económicas, reafirmadas durante la última década en el mundo, se expresan claramente en el debate existente sobre las perspectivas de recuperación después del desastre. Aunque los países poderosos adoptan medidas tendientes a la reactivación de la demanda, el empleo y el consumo, hay una inclinación muy marcada a imponer un retorno a la "vieja normalidad", es decir, al mundo del capital financiero y los grandes negocios. El clamor por la solidaridad por parte de la OMS y la ONU para atender la crisis pareciera haber quedado en el vacío.

Estas tendencias retardatarias impactan de manera negativa a países como Colombia, sumidos en una grave crisis económica y sanitaria. Pero también se convierten en una dificultad adicional para el cumplimiento del Acuerdo de Paz, en particular para el punto1: la Reforma Rural Integral (RRI), la solución al problema de los cultivos ilícitos (punto 4) y la reparación de las víctimas (punto 5). Es claro que, además de decisión política y compromiso estatal, todos ellos requieren de una fuerte y sostenida inversión pública que remedie el abandono histórico por parte del Estado de las regiones más afectadas por el conflicto y priorice el fortalecimiento de la economía campesina sobre los grandes negocios.

\subsection{El contexto regional}

En consonancia con las modificaciones en el orden global, en el ámbito regional también se produjeron cambios importantes. La crisis económica mundial, el derrumbe de los precios de las materias primas y la agenda de la extrema derecha, fortalecida por el mandato de Trump, tuvieron su impacto negativo en el continente y la región. Durante los últimos años se desató una campaña abierta en contra de los llamados gobiernos alternativos latinoamericanos que surgieron y se afianzaron durante la primera década de este siglo.

Algunos de los procesos más álgidos en esta disputa han sido el golpe al Estado Plurinacional de Bolivia, en noviembre de 2019; el permanente 
asedio a la República Bolivariana de Venezuela; así como el endurecimiento del bloqueo y de la política frente a Cuba. Por supuesto que, aparte de la arremetida de las viejas élites de la región aliadas de Washington, estos gobiernos no estuvieron exentos de errores en la conducción del Estado. Pero debe señalarse que algunos de estos países fueron fundamentales en la consolidación de la paz en Colombia y la región.

\subsubsection{La política frente a Venezuela y el conflicto regional}

Aunque en 2015 el gobierno de Obama sentó un precedente grave frente a las relaciones de su país con Venezuela, fue Trump quien decidió desatar una campaña abierta de cerco y aniquilamiento en contra de su gobierno. ${ }^{7}$ Se trataba de derrocarlo, con el objeto de recuperar el control histórico de Washington y de las élites tradicionales sobre el país y sus recursos naturales, en especial el petróleo.

La intensificación de la ofensiva de la Casa Blanca arrancó casi desde los inicios del gobierno Trump. El 8 de agosto de 2017 impulsó la conformación del llamado Grupo de Lima, como una instancia multilateral dirigida a acompañar a la oposición venezolana en su lucha contra el mandato de Nicolás Maduro. Esto sucedió después de que Washington y sus aliados fracasaran en sus repetidos intentos de activar la Carta Democrática de la OEA en contra de este gobierno.

Pero en 2019 la situación se tornó más tensa todavía. El 5 de enero se reunió el Grupo de Lima en la capital peruana, con la participación vía teleconferencia de Mike Pompeo, entonces secretario de Estado de EE. uU. Días después, el 23 de enero, Juan Guaidó, quien era el presidente de la Asamblea Nacional de Venezuela, se autoproclamó presidente

7 El 9 de marzo de 2015, el entonces presidente Obama emitió una orden ejecutiva declarando emergencia nacional la amenaza "inusual y extraordinaria a la seguridad nacional y la política exterior de Estados Unidos”, derivada de la situación de Venezuela (The White House, 2015). Esto sucedió sin la ocurrencia de evento alguno que permitiera justificar la medida. 
encargado del país. Dicha institución era controlada por la oposición y había sido declarada en desacato por el Gobierno nacional.

Días antes, el 10 de enero, el presidente Nicolás Maduro había tomado posesión para su segundo mandato, después de triunfar en unas elecciones que no fueron reconocidas por EE. UU., en cambio, el autoproclamado presidente sí recibió respaldo inmediato: "Hoy, reconozco oficialmente al presidente de la Asamblea Nacional de Venezuela, Juan Guaidó, como el presidente interino de Venezuela", afirmó Trump, al tiempo que llamó a todos los países a proceder de la misma forma ( $L a$ Vanguardia, 2019).

De esta manera se intensificó el bloqueo económico y comercial al país. El 25 de enero Pompeo certificó la potestad del presidente interino para recibir y controlar ciertos bienes en cuentas del Gobierno de Venezuela o del Banco Central de Venezuela, que se encontraban en el Banco de la Reserva Federal u otros bancos asegurados en territorio estadounidense, en consonancia con la Sección 25B de la Ley de la Reserva Federal (USA en español, 2019).

Desde entonces, los ataques contra el Gobierno del país vecino se incrementaron sin cuenta ni medida. Basta recordar algunos episodios: la convocatoria y realización del "concierto humanitario", denominado Venezuela Aid Live, en el puente Tienditas, en la frontera entre Cúcuta y el Táchira, el 22 de febrero del 2019; el intento de levantamiento y golpe de Estado encabezado por Leopoldo López y el mismo Guaidó el 30 de abril siguiente; la incautación de un cargamento de armas que llevaba el exgeneral disidente venezolano, Cliver Alcalá, en la carretera entre Barranquilla y Santa Marta, cuando, según declaró, se dirigía a la frontera en La Guajira, por encargo del autoproclamado presidente, para atentar contra el gobierno de Maduro (El Tiempo, 2020).

A finales de marzo de 2020, en medio de la pandemia y de su campaña electoral, Trump emprendió un despliegue militar en el Caribe y 
el Pacífico, con el pretexto de combatir el narcotráfico proveniente de Venezuela y de México. Pero dejó en claro que se trataba de derribar al gobierno de Nicolás Maduro. En efecto, el 26 de marzo del 2020 EE. UU. lo acusó de narcoterrorismo y ofreció 15 millones de recompensa por su cabeza. "Queremos que sea capturado para que pueda responder por sus acciones en un tribunal estadounidense”, afirmó el entonces fiscal general, Bill Barr. El Departamento de Justicia también presentó cargos contra otros 14 altos funcionarios y exfuncionarios de ese país (France 24, 2020).

Unas semanas antes, el 9 de marzo, se habían iniciado ejercicios militares conjuntos entre Estados Unidos y Colombia en La Guajira, departamento fronterizo con Venezuela, en un operativo que se denominó Ejercicio Vita. Dos meses después, el 27 de mayo, el anuncio de la Embajada estadounidense en Bogotá sobre la llegada de una brigada de Asistencia de Fuerza de Seguridad (SFAB, por sus siglas en inglés), hizo más tensa la situación de la frontera y la región (Embajada de EE.UU. en Colombia, 2020).

Sin embargo, el fallido ataque marítimo perpetrado el domingo 3 de mayo a los estados de Guaira y Aragua, cerca de Caracas, conocido como Operación Gedeón, ha sido de lejos el ataque de mayor envergadura. La reacción de la Fuerza Armada Nacional Bolivariana permitió frustrar el golpe. Al estilo del operativo conocido como Operación Causa Justa, emprendido contra el general Noriega en Panamá, el 20 de diciembre de 1989, se intentó ahora derrocar al mandatario venezolano y apresarlo. Planeaban inmovilizar y capturar también a importantes funcionarios venezolanos, y disponer los aeropuertos Maiquetía y La Carlota para llevarlos a EE. UU. en aviones traídos de ese país. Así lo confesaron Luke Denman y Erin Berry, dos mercenarios estadounidenses exboinas verdes, capturados por el gobierno bolivariano durante el operativo (Pressly, 2020). 
Una vez se frustró el plan, el mandatario venezolano mostró la copia del contrato suscrito entre Juan Guaidó y Jordan Goudreau, excombatiente de Irak y Afganistán, dueño de la empresa de seguridad SilverCorp. Firman como testigos del mismo contrato JJ Rendón, asesor de Guaidó, y Sergio Vergara, sindicado del robo de recursos que se les darían a los militares desertores venezolanos, durante el frustrado operativo del concierto de Cúcuta. El objeto del contrato era entrenar mercenarios en La Guajira colombiana y realizar operaciones encaminadas a la salida de Maduro del poder. Su monto fue de más de \$200 millones de dólares, que provendrían de la venta de petróleo de la empresa petrolera Citgo, confiscada por Trump al gobierno de Venezuela (Guerra, 2020).

El operativo fue todavía más tenebroso, en lo que respecta a los vínculos colombianos. El entrenamiento de entre 70 y 80 personas que participaron en él se hizo en tres campamentos situados en una finca de Elkin Javier López Torres, alias "la Silla" o "Doble Rueda”, un poderoso narcotraficante de la llamada Oficina Caribe. Debe recordarse también que miembros de la banda "los Rastrojos" ayudaron a Guaidó a atravesar la frontera para llegar a Cúcuta al concierto, cuyo jefe de seguridad fue el mismo Jordan Goudreau. He ahí el despliegue y la actividad del narcotráfico en todo su esplendor. JJ Rendón, asesor del autoproclamado presidente, reconoció la validez del contrato y señaló que este hacía parte de un mismo plan para derrocar a Maduro, ideado por el llamado Comité Estratégico, que se conformó en Miami para adelantar dicha tarea (Connectas, 2020).

La participación del gobierno de Iván Duque y de las fuerzas armadas del país quedó demostrada. Seis días después del ataque marítimo, tres lanchas artilladas con ametralladoras, fusiles y munición de la Armada colombiana que estaban sobre el río Meta, aparecieron en Venezuela, sobre el río Orinoco. Más recientemente, en enero 2021, la venezolana Yacsy Álvarez, una de las participantes en la operación Gedeón, reconoció la intervención del Gobierno colombiano en este operativo (Semana, 2021). 


\subsubsection{El giro frente a Cuba}

El 11 de enero del 2021, todavía bajo la conmoción causada por la toma del Capitolio por los partidarios de Trump, y a pocos días de salir de la Casa Blanca, el ahora expresidente decidió incluir de nuevo a Cuba en la lista de países que patrocinan el terrorismo. Aunque la decisión provocó rechazo en el mundo entero, pasó prácticamente inadvertida debido al escándalo y la incertidumbre reinantes.

Esta lista fue concebida en diciembre de 1979 por el Departamento de Estado, en plena Guerra Fría, con base en la sección 40 de la Ley de exportación de armas. De manera arbitraria, le permite a Washington amenazar y sancionar a países soberanos, conforme a sus propios intereses y políticas imperiales. En 1982 el gobierno de Reagan incluyó a Cuba en esa lista. Las sanciones son diversas: prohibición de venta de armas, restricciones económicas y financieras, bloqueo de créditos en el Banco Mundial y otras entidades.

El proceso de restablecimiento de las relaciones diplomáticas y comerciales con Cuba, emprendido por Barack Obama con la mediación del papa Francisco, se conoció el 17 diciembre de 2014. Meses después, el 20 de julio de 2015, cuando había transcurrido más de medio siglo de la ruptura unilateral de las relaciones diplomáticas, Obama anunció su restablecimiento formal y el retiro de Cuba de la mencionada lista (Telesur, 2015). Un punto culminante de este proceso fue el histórico encuentro entre el ahora expresidente con Raúl Castro, en La Habana, el 21 de marzo de 2016.

Pero todo eso quedó en el pasado. En desarrollo de su agresiva política exterior frente a este país insular, Trump decidió darle marcha atrás a este proceso. El canciller cubano Bruno Rodríguez analizó las implicaciones de este giro político y se refirió a la aplicación de 240 medidas coercitivas unilaterales, tendientes a revertir las adoptadas por Obama. Impuso nuevas y fuertes restricciones para intercambios turísticos y cruceros, ingreso de aviones privados y vuelos chárter, y envío de remesas. A través de 
Twitter expreso: "El gobierno de Trump, al proponerse deshacer el legado Obama/Biden en política exterior, arremetió contra Cuba con particular ensañamiento y con el respaldo de una feroz campaña de difamación” (Telesur, 2021b).

Así, la estocada final contra Cuba se fue preparando durante el último año de gobierno de Donald Trump. Meses atrás, Washington ya la había incluido en la lista de los países que no toman ninguna medida frente al tráfico de personas. A esto se sumó la inclusión de 231 empresas cubanas, la mayor parte de ellas del sector turístico, su principal motor económico, en las “listas negras” elaboradas por el Departamento de Estado.

Al mismo tiempo, Washington desató una persecución financiera destinada a privar de ingresos y nuevas líneas de crédito a Cuba, que incluyó la imposición de millonarias multas a bancos extranjeros que hicieran operaciones con el país, y la reducción de su capacidad de adquisición e importación de productos esenciales. Se esforzó por boicotear e impedir la entrada de combustibles y amenazó con severas multas a navieras, aseguradoras y buques que participaran en el abastecimiento de petróleo. El bloqueo, y las sanciones y amenazas, incluso a terceros países, se hicieron más fuertes y dolorosas en medio de la crisis sanitaria, mientras Cuba cumplía un papel ejemplar con el despliegue de misiones médicas a más de 70 países del mundo entero, muchos de ellos con condiciones precarias para atender la pandemia.

Sin embargo, fue el gobierno de Iván Duque el que le proporcionó a Trump el pretexto para inscribirlo en forma definitiva en la temible lista de países que respaldan el terrorismo. El motivo que adujo Trump fue el no haber atendido la solicitud hecha por el Gobierno colombiano, para que extraditara a los dirigentes del ELN que integraron la delegación de paz, con motivo del repudiable atentado de este grupo en la Escuela de Cadetes de Bogotá, en enero de ese año, que dejó un saldo de 21 muertos (Swi, 2019). 
Con esta medida desconoció los protocolos suscritos el 5 de abril de 2016 por el Estado colombiano, la guerrilla y los países garantes, para el caso de que se diera una ruptura de la negociación. En una manifestación de cinismo e ingratitud a toda prueba, el Gobierno colombiano celebró a viva voz el apoyo recibido de la Casa Blanca. Por el futuro inmediato, parece alejarse cualquier posibilidad de salida negociada al conflicto armado con el ELN.

Al respecto, señala Humberto de La Calle, negociador del Gobierno nacional en el proceso con las FARC-EP de La Habana:

Los protocolos suscritos para los miembros del ELN obedecen a una práctica milenaria sin la cual se harían imposibles las conversaciones entre antagonistas armados (...) Es inaudito que se acuse a Cuba por honrar la palabra empeñada con el gobierno de Colombia. La afirmación de que fue suscrito 'con otro gobierno' carece de toda validez internacional. (2020, párrs. 2 y 4).

Dado que Cuba se mantuvo firme en la posición de respetar sus compromisos como país garante, tal y como le correspondía, Colombia emprendió su retaliación. Por primera vez en la historia, en la Asamblea de la ONU del 2020 se abstuvo en la votación anual que se hace para condenar el bloqueo de EE. UU. contra la isla. La diplomacia colombiana para incluir a Cuba en la lista de las naciones que patrocinan el terrorismo había alcanzado su objetivo. Debe tenerse en cuenta que esta diplomacia es ejercida principalmente por Francisco Santos, desde la Embajada en Washington, y Alejandro Ordóñez, en la OEA. Son los mismos que junto con sus aliados de la extrema derecha republicana pusieron al Gobierno colombiano al servicio de la campaña electoral de Trump, causándole serios problemas con el Partido Demócrata y el nuevo Gobierno. 
Pero Duque siguió trabajando en contra de Cuba. Sin mostrar evidencia alguna, desde hace un tiempo ha querido hacer ver a su embajador en Colombia como un conspirador dedicado a imponer gobernantes de izquierda radical en toda América Latina, una acusación publicada por la revista Semana (2021), hoy vocera de la extrema derecha.

La situación para Cuba en lo que respecta a esta sanción no es fácil. Es cierto que hay presión por parte de algunos congresistas y de sectores de la producción y el comercio en EE. UU. para que las relaciones con Cuba retomen su curso. Pero también sucede que, sumido en la enorme crisis en la que su antecesor dejó al país, el gobierno de Biden tiene otras prioridades políticas, sociales y económicas. Asimismo, existen presiones en contra para revertir la medida contra Cuba, un proceso que además tendría que pasar por todos los organismos de inteligencia, comercio, tesoro, defensa, lo que podría tardar varios meses.

\section{El Acuerdo de Paz y la "comunidad internacional"}

\subsection{Colombia vs. Naciones Unidas}

Pese a las tendencias negativas descritas, entidades internacionales como la ONU y la CPI han desempeñado un papel relevante en cuanto a la implementación del Acuerdo de Paz, y su apoyo y acompañamiento han sido permanentes.

La Carta de las Naciones Unidas se suscribió en San Francisco en 1945 y dio origen a la primera de estas instituciones. Como consta en su preámbulo, se propuso como objetivo "crear condiciones bajo las cuales puedan mantenerse la justicia y el respeto a las obligaciones emanadas de los tratados y de otras fuentes del derecho internacional". Así, su desarrollo y el respeto por este derecho han sido elementos fundamentales de su trabajo (ONU, 2021). El derecho internacional establece las responsabilidades legales de los Estados en el ámbito internacional frente a asuntos como derechos humanos, 
preservación de la paz, desarme, delitos internacionales, refugiados, migraciones, uso de la fuerza, entre otros. Por ello, pese a todas sus limitaciones y vacilaciones, y a la manipulación ejercida por los países poderosos, la ONU es la única entidad con posibilidad de preservar el orden legal y unas garantías mínimas de paz y convivencia en el orbe.

El Estatuto de Roma, por su parte, fue adoptado en julio de 1998, durante la Conferencia Diplomática de Plenipotenciarios de las Naciones Unidas sobre el Establecimiento de una Corte Penal Internacional. Esta Corte entró en funcionamiento en julio de 2002 y tiene competencia para conocer los diversos crímenes de guerra, lesa humanidad y otros, y llevarlos ante la justicia. De conformidad con el principio de complementariedad, la CPI actuará solo cuando los tribunales nacionales se muestren incapaces para ejercer su jurisdicción o muestren su renuencia a hacerlo.

La Corte ha venido haciendo un cuidadoso seguimiento del caso de Colombia en asuntos centrales que le competen, y le ha brindado respaldo permanente a la JEP, destacándola como el mecanismo clave de la justicia transicional consagrado en el Acuerdo de Paz. Precisamente lo ha hecho ante los mayores ataques propinados por el Gobierno y la Fiscalía. En noviembre de 2018, su vicefiscal James Stewart observó: "Permitan que los magistrados de la JEP hagan su trabajo. Apóyenlos en todos los aspectos que sean necesarios” (JEP, 2019). Asimismo, la CPI ha expresado su confianza en que no habrá amnistías ni indultos para crímenes de guerra o delitos de lesa humanidad.

En lo que respecta a la ONU, Ban ki-moon, su anterior secretario general, se comprometió personalmente durante todo el proceso de negociación y asistió a su firma inicial en Cartagena el 26 de septiembre de 2016. "Lo que han perdido nunca será reparado. Sin embargo, las víctimas han estado entre las voces más firmes a favor de la paz y la reconciliación y en contra de la amargura y el odio. Su ejemplo debe servir de inspiración para todos” señaló (ONU, 2016). Ratificó el compromiso de la ONU y de 
su misión política en Colombia con la ayuda a la implementación del Acuerdo de Paz y con la superación de los desafíos existentes en materia humanitaria y de derechos humanos, y agradeció y reconoció el papel de los países garantes y acompañantes. En enero de 2018 su sucesor, Antonio Guterres, visitó Colombia y declaró: “La paz es la única respuesta que hoy puede dar solución a los problemas de la pobreza, a los problemas del desarrollo y a los problemas de la igualdad y la democracia” (ONU, 2018).

El gobierno de Duque ha estado en tensión y conflicto permanente con dichas entidades. En más de una ocasión, sus funcionarios han viajado a las entidades de Naciones Unidas para tratar de explicarles lo inexplicable sobre sus incumplimientos frente al Acuerdo de Paz y el tratamiento de los derechos humanos. Debe recordarse que el Consejo de Seguridad se comprometió a fondo con el Acuerdo, ha sesionado en Colombia y ha hecho repetidas declaraciones expresando su respaldo, prueba de lo cual es la Misión de Verificación, encargada de verificar la reincorporación política, económica y social, así como las garantías de seguridad para los reincorporados de las FARC-EP, sus familias y las comunidades en donde hoy están asentados.

Aunque las contradicciones han sido múltiples, en general estas se han originado en informes de la entidad que han provocado rechazo y molestia en el Gobierno. Uno de ellos fue el presentado el 25 de febrero del 2020 por Alberto Brunori, entonces representante en Colombia de la Oficina de la Alta Comisionada de las Naciones Unidas para los Derechos Humanos (ACNUDH). Este informe documenta los riesgos a los que están expuestos los defensores de derechos humanos y expresa su preocupación por las falencias en la implementación del Acuerdo y por las disidencias de las FARC-EP, al tiempo que destaca los avances de la JEP. El gobierno de Duque lo descalificó, señalándolo como violatorio de la soberanía nacional, pero el informe recibió el respaldo de las embajadas de Canadá, Noruega y Francia en Colombia (ONU, 2020b). 
Otro enfrentamiento, también con la Oficina de derechos humanos de la ONU, se dio por el informe sobre el país, presentado por el Relator Especial de las Naciones Unidas sobre la situación de los defensores de derechos humanos, Michael Forst, ante el Consejo de Derechos Humanos de ese organismo, el 4 de marzo del 2020 en Ginebra. Este fue respaldado de inmediato por todos los países, que llamaron a Colombia a cumplir con las recomendaciones planteadas. No obstante, en este caso el malestar venía desde meses atrás. A este funcionario el Gobierno no le extendió invitación para regresar al país a terminar su trabajo, debido al disgusto que provocó su primer informe de 2018, producido después de su visita entre noviembre 20 y diciembre 3 de ese año, cuando se reunió con autoridades nacionales y locales, miembros de la sociedad civil y de la comunidad internacional.

En su informe final, Forst afirma que Colombia es el país con mayor índice de asesinatos de defensores de derechos humanos en Latinoamérica y resalta sus altos índices de impunidad frente a los homicidios de estos y de líderes/as. El Relator habla de un esclarecimiento de solo el $11 \%$ de los casos y señala que los altos índices de impunidad que caracterizan las agresiones a las personas defensoras de derechos humanos contribuyen a perpetuar este ciclo de violencia (ONU, 2020a, p. 8). Agrega que un asunto fundamental para propiciar un entorno seguro de defensa de los derechos humanos es investigar, juzgar y sancionar a los autores materiales e intelectuales comprometidos con todo tipo de agresiones cometidas.

Forst destaca como profundamente grave el hecho de que personas defensoras de derechos humanos sean criminalizadas por "pertenecer a grupos armados ilegales, como las extintas FARC-EP o el ELN”. Señala casos concretos y se refiere también al posible papel que podrían jugar en esas judicializaciones grandes empresas que ejecutan megaproyectos energéticos. Destaca la existencia de "un patrón constante de alto número de asesinatos y otras violaciones” (p. 6). 
En efecto, el término “sistematicidad” ha generado enfrentamiento permanente entre la ONU y el Gobierno nacional y la Fiscalía. Tal como lo señala el Programa Somos Defensores (2020), “los casos hablan por sí mismos y demuestran el fracaso del Plan Acción Oportuna (PAO) del gobierno Duque, lanzado el 20 noviembre de 2018, y la validez de los argumentos al respecto” (p. 181). Las organizaciones de derechos humanos han puesto de presente que el diagnóstico del Gobierno se niega a asumir un análisis multicausal del problema y carece de voluntad para implementar las garantías consagradas en el Acuerdo de Paz, lo que se suma a la ya persistente impunidad. ${ }^{8}$

Toda esta situación llevó a la Alta Consejería para los Derechos Humanos de la ONU a declarar la defensa de los derechos humanos como una actividad de alto riesgo en Colombia. De la misma manera, el Informe Brunori, antes mencionado, denunció el alto número de asesinatos de líderes indígenas y hace un llamado de atención específicamente frente a los crímenes étnicos. Exhortó al Gobierno para avanzar en la implementación del Acuerdo de Paz, principalmente en cuanto a la restitución de tierras, ubicando a las víctimas como eje de dicha implementación. Llama también a entender que la distribución de la tierra es una de las causas históricas del conflicto colombiano.

Así mismo, este informe hace sugerencias importantes sobre el Ejército y la Policía. Frente al primero, pide investigar los casos de ejecuciones extrajudiciales y los registros de tortura, así como los casos de cooperación entre fuerzas armadas y grupos paramilitares (ONU, 2020b, p. 13). En cuanto a la Policía, recomienda su traslado del Ministerio de Defensa al Ministerio del Interior. También pide investigar los casos de violaciones a los derechos humanos, como episodios de tortura y vejámenes a

8 El programa Somos Defensores (2020) destaca que hasta los casos que se están indagando y no tienen imputación de cargos son considerados por el Gobierno como resultados notorios en materia de esclarecimiento, lo que resulta vergonzoso (p. 180). 
la dignidad de civiles. Hace un llamado a transformar el accionar del Escuadrón Móvil Antidisturbios, teniendo en cuenta lo sucedido en el paro del 21 de noviembre y el asesinato de Dilan Cruz, y pide que sea la justicia ordinaria y no la Justicia Penal Militar la que investigue las violaciones a los derechos humanos.

La reacción del Gobierno, en cabeza del presidente Duque, al informe presentado por Alberto Brunori, representante de la Oficina de Derechos Humanos de la ONU en Colombia, consistió en descalificarlo en su totalidad y en cuestionar sus recomendaciones. El entonces ministro de Defensa, Carlos Holmes Trujillo, señaló que

“el Gobierno Nacional ve con profunda sorpresa y extrañeza que el informe contiene afirmaciones que atacan la legitimidad de las instituciones que son imprecisas y al parecer desbordan el mandato que ha suscrito el gobierno con la oficina de la Alta Comisionada para los derechos humanos". (Torrado y Oquendo, 2020).

Aparte de los conflictos mencionados, el Gobierno canceló otras actividades de las agencias de la ONU en Colombia, entre ellas el convenio con la Oficina de las Naciones Unidas contra las Drogas y el Delito, que brindaba asistencia técnica al Programa Nacional Integral de Sustentación de Cultivos (PNIS). Dicho programa es central para el cumplimiento del punto 4 del Acuerdo de Paz, sobre solución al problema de las drogas ilícitas, por cuanto le apunta a la sustitución voluntaria. El Gobierno nacional también se ha negado a aprobar solicitudes de visitas de otros expertos de derechos humanos en temas como el agua, desplazamiento interno, justicia transicional, salud, derechos de los migrantes, sustancias y desechos peligrosos y tóxicos, detenciones arbitrarias y discriminación, y violencia contra las mujeres.

Pero el cuestionamiento al Gobierno por no cumplir con el Acuerdo de Paz, y en particular por la ineficiencia de sus medidas para frenar el 
extermino de líderes/as sociales y excombatientes, proviene también de otras entidades. Human Rights Watch publicó en febrero 2021 un informe muy crítico al respecto. Allí se documentan los asesinatos de defensores de derechos humanos en seis de las zonas más afectadas por la violencia en el país. El informe llama la atención sobre el hecho de que las autoridades no ejercen un control efectivo sobre varias zonas que previamente estaban en poder de las FARC-EP. Analiza también las falencias de las políticas del Gobierno para prevenir los asesinatos. Destaca que el despliegue de tropas en algunas regiones se hace sin fortalecer la justicia ni las oportunidades económicas y sociales para la población. Hace una serie de recomendaciones muy precisas al presidente, al Congreso, la Fiscalía, la Defensoría del Pueblo y organismos de control, gobiernos territoriales y países donantes (Human Rights Watch, 2021).

\subsection{Estados Unidos y el Acuerdo de Paz}

En el contexto internacional antes presentado, el gobierno de Trump introdujo también un cambio de fondo en la política de Washington frente al Acuerdo de Paz y su implementación. Aunque al principio pretendió ignorarlo, en la práctica se dedicó a entorpecerlo y sabotearlo. Un contraste claro con el gobierno Obama/Biden, que durante todo el proceso de La Habana con las antiguas FARC-EP mostró su compromiso enviando a Bernard Aronson como su delegado durante la negociación.

La posición contraria de su sucesor se expresó de diversas maneras. En un acto de abierta intervención en los asuntos internos de Colombia, por lo demás bastante frecuentes, en abril de 2019 el entonces embajador en el país, Kevin Whitaker, se reunió con seis representantes a la Cámara. Entre intimidaciones y amenazas, les expresó su preocupación por su postura frente al proyecto de objeciones a la ley estatutaria de la JEP, presentado por el Gobierno para entrabarla. El embajador intentó proceder de la misma manera con los magistrados 
de la Corte Constitucional, pero estos se negaron a reunirse con él. A algunos congresistas y magistrados se les canceló la visa estadounidense como represalia (RCN, 2019). Asimismo, desde bien pronto Trump conminó a Duque a dar paso a la fumigación aérea de cultivos ilícitos, contraviniendo así lo establecido en el Acuerdo de Paz en cuanto a privilegiar la sustitución voluntaria. Por último, durante la última campaña electoral, Trump se pronunció abiertamente en contra del Acuerdo y quienes lo negociaron.

Con el gobierno de Joseph Biden, es claro que las prioridades comienzan a cambiar. El senador demócrata Patrick Leahy se refirió al contenido del informe arriba mencionado de Human Rights Watch sobre la deficiente respuesta del gobierno de Duque a los asesinatos de líderes/ as de derechos humanos, con términos muy duros. Señaló que estos asesinatos eran "espantosos" y que era lamentable que el Gobierno no avanzara en las medidas para evitar la violencia desbordada contra estos líderes. "El acuerdo de paz no puede sobrevivir si esto continúa porque estas personas arriesgaron sus vidas para apoyarlo y son esenciales para su éxito”, señaló (Caracol, 2021). Un año atrás, en abril de 2020, este mismo senador encabezó una dura carta al presidente Duque expresándole su consternación por la designación de altos mandos del Ejército, a pesar de que existían informes creíbles de su vinculación con falsos positivos (Human Rights Watch, 2020).

En el mismo sentido, el portavoz del Departamento de Estado, Ned Price, señaló que una de las “máximas prioridades” para el presidente Biden es aclarar los asesinatos de líderes sociales en Colombia. Calificó como insuficientes los esfuerzos del Gobierno para frenar las amenazas y los asesinatos. Recalcó que los defensores de derechos humanos desempeñan un papel vital en la construcción de una paz justa y duradera en Colombia (Radio Nacional, 2021). 


\section{Conclusión: ¿hacia un entorno internacional más favorable?}

La implementación del Acuerdo de Paz se ha visto muy golpeada durante el gobierno del Centro Democrático, encabezado por el presidente Iván Duque. Su coincidencia temporal con el mandato de Trump en la Casa Blanca hizo todavía más difícil la situación. Sin embargo, pese a las dificultades, es claro que la supervisión permanente ejercida por la ONU, la CPI y otros organismos internacionales ha sido definitiva para que la extrema derecha no haya podido cumplir con su propósito de "hacer trizas el Acuerdo de Paz".

Las condiciones políticas internacionales desfavorables para el Acuerdo parecieron empezar a modificarse con el gobierno de Biden. Aunque es cierto que en términos generales su triunfo representa la continuidad de la política exterior del país y de su carácter claramente imperialista, sí hay algunas modificaciones importantes que favorecen la implementación del Acuerdo. Su defensa, así como la de la vida de los líderes y lideresas sociales, es significativa e importante.

Podría esperarse también que el nuevo mandatario retome la senda de Obama en las relaciones con Cuba y suavice un tanto las tensiones frente a Venezuela, aunque esto último parece menos probable. En todo caso, el cambio en la Casa Blanca brinda condiciones más propicias para librar la batalla por unas relaciones internacionales de respeto entre los países, lo que le conviene a la región y a los pueblos del mundo.

En el plano regional también se han desarrollado tendencias favorables en los últimos tiempos. Los triunfos electorales de Andrés Manuel López Obrador en México, en 2018 y de Alberto Fernández en Argentina un año después, abrieron la perspectiva de una nueva ola de gobiernos progresistas, no exentos de contradicciones. A ello siguió el retorno al poder del Movimiento al Socialismo (MAS) en Bolivia, un año después 
del golpe y el triunfo del plebiscito para cambiar la Constitución en Chile, la semana siguiente. Estos cambios en la región terminan por favorecer el proceso de consolidación de la paz en Colombia.

En los momentos en que esto se escribe, se produce una portentosa movilización social en Colombia, con resultados imprevisibles. La comunidad internacional y los sectores democráticos del mundo entero han repudiado la respuesta militar, de corte fascista, que viene dando el Gobierno colombiano a la lucha social, que ha dejado un número importante de muertos, desaparecidos, torturados y encarcelados, fundamentalmente entre la juventud de la ciudad y el campo. Además de la profunda crisis económica y social, una denuncia permanente en esta movilización ha sido el incumplimiento de lo pactado en el Acuerdo de Paz por parte del Gobierno.

Pese a tan serias dificultades, el pulso por la paz se sigue dando en todo el territorio nacional, en especial en las regiones más golpeadas, que sobreviven entre la resistencia y la movilización social. La defensa del Acuerdo de Paz y de la vida sigue siendo el asunto central.

\section{Referencias bibliográficas}

Berkhout, Esmé; Galasso, Nick; Lawson, Max; Rivero, Pablo; Taneja, Anjela; Vázquez, Diego. (2021). El virus de la desigualdad. Cómo recomponer un mundo devastado por el coronavirus a través de una economía equitativa, justa y sostenible. Oxfam. International. Recuperado de https://www. oxfam.org/es/informes/el-virus-de-la-desigualdad

Cancillería de Colombia. (2018). Principios y lineamientos de la política exterior colombiana 2018-2022. Recuperado de: https://www.cancilleria.gov. co/principios-y-lineamientos-la-politica-exterior-colombiana

Caracol Radio. (11 de febrero de 2021). Acuerdo de Paz no puede sobrevivir si muertes de líderes continúan. Recuperado de https://caracol.com.co/ radio/2021/02/11/internacional/1613051303_325290.html 
Centro de Investigación y Educación Popular/Programa por la Paz [Cinep-Ppp]. (2019). ¿Cuál es el pacto en el Plan Nacional de Desarrollo? Diálogos Cinep/ Programa por la Paz. Recuperado de https://www.cinep.org.co/Home2/ component/k2/693-cual-es-el-pacto-en-el-plan-nacional-de-desarrollo.html

Centro Nacional de Memoria Histórica [CNMH]. (2013). ¡Basta ya! Colombia: memorias de guerra y dignidad. Bogotá: Autor.

Connectas. (7 de mayo de 2020). J.J. Rendón habla sobre la Operación Gedeón en Conclusiones de CNN en Español. Recuperado de https://www.connectas.org/jj-rendon-confirma-contrato-ataque-maduro-venezuela/

Contexto Diario. (27 de agosto de 2018). Colombia le dijo adiós a la Unasur. Recuperado de https://contextodiario.com/internacional/colombia-le-dijoadios-a-la-unasur/

Cortina, Adela. (6 de marzo de 2000). Aporofobia. El País, edición impresa, España. Recuperado de https://elpais.com/diario/2000/03/07/opinion/952383603_850215.html

De La Calle, Humberto. (17 de mayo de 2020). Cuba ha apoyado la paz, Recuperado de http://www.eje21.com.co/2020/05/cuba-ha-apoyado-la-paz/

El Tiempo. (26 de marzo de 2020). Venezolano buscado por Estados Unidos dice ser dueño de fusiles incautados. Recuperado de https://www.eltiempo.com/unidad-investigativa/uno-de-los-buscados-por-ee-uu-dice-serdueno-de-fusiles-incautados-en-colombia-477412

Embajada de EE. UU. en Colombia. (27 de mayo de 2020). Misión SFBA viene a Colombia. Recuperado de https://co.usembassy.gov/es/ mision-sfab-viene-a-colombia/

France 24. (27 de marzo de 2020). EEUU inculpa de "narcoterrorismo" a Maduro y ofrece millonaria recompensa para detenerlo. Recuperado de https:// www.france24.com/es/20200326-eeuu-inculpa-de-narcoterrorismo-a-maduro-y-ofrece-millonaria-recompensa-para-detenerlo-1

Gneiting, Uwe; Lusiani, Nicholas y Tamir, Irit. (10 de septiembre de 2020). Poder, ganancias y pandemia. De una economía para las élites a una economía para las personas. Oxfam International. Recuperado de https://www. oxfam.org/es/informes/poder-ganancias-y-pandemia 
Gobierno de Colombia. (26 de septiembre de 2018). Ante la ONU, Presidente Duque pide al mundo actuar para detener éxodo trágico y que en Venezuela renazca la esperanza. Recuperado de https://id.presidencia.gov.co/Paginas/ prensa/2018/180926-Ante-la-ONU-Presidente-Duque-pide-al-mundo-actuarpara-detener-exodo-tragico-y-que-en-Venezuela-renazca-la-esperanza.aspx

Guerra, Carlos Armando. (15 de mayo de 2020). El caso de la "Operación Gedeón” estremeció la movediza arena política venezolana. Correo del Caroni. Recuperado de https://www.correodelcaroni.com/pais-politico/el-caso-dela-operacion-gedeon-estremecio-la-movediza-arena-politica-venezolana/

Human Rights Watch. (2020). Informe mundial 2020. Recuperado de https:// www.hrw.org/es/world-report/2020/country-chapters/336672\#

Human Rights Watch. (Febrero, 2021). Lideres desprotegidos y comunidades indefensas. Asesinatos de defensores de derechos humanos en zonas remotas de Colombia. Recuperado de https://www.hrw.org/sites/default/files/ media_2021/02/colombia0221sp_web.pdf

Indepaz. (19 de abril de 2021). \#CONLIDERESHAYPAZ. Agresiones contra la paz en Colombia. Noviembre 2016 - Abril 19 de 2021. Recuperado de http://www.indepaz.org.co/wp-content/uploads/2021/04/CONLI\%CC \% 81DERES-HAY-PAZ.pdf

Justicia Especial para la Paz [JEP]. (20 de febrero de 2019). Corte Penal Internacional insiste en que JEP tenga un marco legal definido. Recuperado de https://www.jep.gov.co/Sala-de-Prensa/Paginas/Corte-Penal-Internacional-insiste-en-que-JEP-tenga-un-marco-legal-definido.aspx

Klare, Michael. (2001). Resource wars: the new landscape of global conflict. Nueva York: Henry Holt \& Company.

La Vanguardia. (23 de enero de 2019). El opositor Guaidó se proclama presidente de Venezuela y Trump lo reconoce. Recuperado de https://www. lavanguardia.com/internacional/20190123/454276264739/lider-opositorguaido-presidente-venezuela-protestas-maduro-trump.html

Misión de Verificación de la ONU en Colombia. (13 de enero de 2018). Declaración del Secretario General de Naciones Unidas, António Guterres, Recuperado de https://colombia.unmissions.org/declaraci\%C3\%B3n-delsecretario-general-de-naciones-unidas-ant \% C3\% B3nio-guterres 
Organización de las Naciones Unidas [ONU]. (2012). Situación y perspectivas de la economía mundial. . https://www.un.org/en/development/desa/ policy/wesp/wesp_current/2012wesp_es_sp.pdf

Organización de las Naciones Unidas. (26 de septiembre de 2016). “¡Viva Colombia en paz!”, dice Ban Ki-Moon. Noticias ONU. Recuperado de https:// news.un.org/es/story/2016/09/1365511

Organización de las Naciones Unidas. (21 de enero de 2018). "La paz es la única respuesta”: António Guterres. Recuperado de https://nacionesunidas. org.co/noticias/la-paz-es-la-unica-respuesta-antonio-guterres/

Organización de las Naciones Unidas. (4 de noviembre de 2019). ¿Nueva crisis económica global?: 4 países al borde de la recesión rumbo a 2020. Recuperado de https://actualidad.rt.com/ actualidad/332285-crisis-economica-global-4-paises-recesion

Organización de las Naciones Unidas. (4 de marzo de 2020a). Informe del Relator Especial sobre la situación de los defensores de los derechos humanos acerca de su visita a Colombia - Comentarios formulados por el Estado (A/HRC/43/51/ Add.4). Recuperado de https://undocs.org/es/A/HRC/43/51/Add.4

Organización de las Naciones Unidas. (25 de febrero de 2020b). Informe de la Alta Comisionada de las Naciones Unidas para los Derechos Humanos sobre la situación de los derechos humanos en Colombia. Recuperado de https://www.hchr.org.co/index.php/informes-y-documentos/informesanuales/9136-informe-del-alto-comisionado-de-las-naciones-unidas-paralos-derechos-humanos-sobre-la-situacion-de-derechos-humanos-en-colombia-durante-el-ano2019

Organización de las Naciones Unidas. (2021). Defender el derecho internacional. Recuperado de https://www.un.org/es/sections/what-we-do/ uphold-international-law/

Presidencia de la República. (17 de diciembre de 2018). Presentación de la Política de Estabilización "Paz con legalidad". Recuperado de https:// id.presidencia.gov.co/Paginas/prensa/2018/181217-Presentacion-PoliticaEstabilizacion-Paz-Legalidad.aspx 
Pressly, Linda. (13 de agosto de 2020). "Cómo se planeó la Operación Gedeón, la fallida "misión suicida" que buscaba capturar a Nicolás Maduro. BBC News. Recuperado de https://www.bbc.com/mundo/ noticias-america-latina-53710482

Programa Somos Defensores. (2020). ¡Ni pio, ni PAO! No paran agresiones a las personas defensoras de derechos humanos. En El desgobierno del aprendiz. Autoritarismo, guerra y pandemia. Balance del segundo año del gobierno de Iván Duque. Bogotá: AA. VV.

Radio Nacional de Colombia. (11 de febrero de 2021). Estados Unidos expresó preocupación por asesinato de líderes sociales en Colombia. Recuperado de https://www.radionacional.co/noticia/estados-unidos/estados-unidosexpreso-preocupacion-asesinato-de-lideres-sociales-colombia

RCN Radio. (3 de abril de 2019). ¿Para qué se reunió embajador de EE. UU. con congresistas, por objeciones a la JEP? Recuperado de https://www.rcnradio.com/politica/para-que-se-reunio-embajador-de-eeuu-con-congresistaspor-objeciones-la-jep

Rodríguez, Ana M. (8 de octubre de 2020). Intervención en el lanzamiento virtual del informe El desgobierno del aprendiz. Bogotá: Plataforma Colombiana de Derechos Humanos, Democracia y Desarrollo.

Semana. (28 de enero de 2021). Operación Gedeón: una de las involucradas afirma que inteligencia colombiana conocía del plan para derrocar a Maduro. Recuperado de https://www.semana.com/nacion/articulo/operaciongedeon-una-de-las-involucradas-afirma-que-inteligencia-colombiana-conocia-del-plan-para-derrocar-a-maduro/202153/

Sánchez-Garzoli, Gimena y Haugaard, Lisa. (29 de septiembre de 2020). Estados Unidos requiere que se consolide la paz para lograr sus metas en Colombia. En El desgobierno del aprendíz. Bogotá: Plataforma Colombiana de Derechos Humanos, Democracia y Desarrollo.

SWI swissinfo.ch. (22 de enero de 2019). Colombia reitera solicitud a Cuba para que extradite a miembros del ELN. Recuperado de https://www.swissinfo.ch/spa/colombia-reitera-solicitud-a-cuba-para-que-extradite-a-miembros-del-eln/44700954 
TeleSURtv.net. (22 de julio de 2015). Restablecimiento histórico de las relaciones diplomáticas entre Cuba y Estados Unidos. Recuperado de https:// www.telesurtv.net/analisis/Restablecimiento-historico-de-las-relacionesdiplomaticas-entre-Cuba-y-Estados-Unidos-20150722-0034.html

TeleSURtv.net. (19 de enero de 2021a). Programa Jugada crítica, entrevista. Caracas, Venezuela. Recuperado de. https://mi.tv/sv/canales/ telesur/2021-01-19

TeleSURtv.net. (19 de enero de 2021b). Canciller cubano llama "fracaso" a política de Trump hacia Cuba. Recuperado de https://www.telesurtv.net/ news/canciller-fracaso-eeuu-cuba-20210119-0029.html

The White House: Office of the Press Secretary. (9 March, 2015). FACT SHEET: Venezuela Executive Order, recuperado de https:// obamawhitehouse.archives.gov/the-press-office/2015/03/09/ fact-sheet-venezuela-executive-order?rel $=$ mas

Torrado, Santiago y Oquendo, Catalina. (4 de marzo de 2020). Un nuevo informe sobre derechos humanos aumenta la tensión entre el gobierno colombiano y la ONU. El País, Madrid. Recuperado de https://elpais.com/ america/internacional/2020-03-04/un-nuevo-informe-sobre-derechos-humanos-aumenta-la-tension-entre-el-gobierno-colombiano-y-la-onu.html

USA en Español. (29 de enero de 2019). ¡Proteger los activos de Venezuela en beneficio del pueblo venezolano. Declaración del portavoz adjunto Palladino. Recuperado de https://medium.com/@USAenEspanol/reuni\%C3\%B3ndel-secretario-pompeo-con-el-grupo-de-lima-a2dcb8201c6e 